Nunt. Antiquus, Belo Horizonte, v. 14, n. 2, p. 195-216, 2018

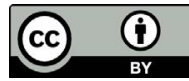

\title{
A imitação de Ovídio e as estratégias de Marcial
}

\section{The Imitation of Ovid and Martial's Strategies}

\author{
Fábio Paifer Cairolli \\ Universidade Federal Fluminense (UFF), Niterói, Rio de Janeiro / Brasil \\ cairolli@yahoo.com.br
}

\begin{abstract}
Resumo: O presente artigo analisa um conjunto de passagens de Marcial em que este autor emula a poesia de Ovídio, e tem o objetivo de compreender as estratégias que Marcial emprega na apropriação de material da obra de Ovídio. Partindo da classificação de Cenni (2009), que divide as passagens de seu corpus em citações (citazioni) e ecos (riecchegiamenti), conclui-se que os procedimentos de Marcial são mais complexos do que a dicotomia proposta pela pesquisadora italiana e propõe-se uma tipologia que classifica a atividade de emulação de Ovídio por Marcial em reminiscência, justaposição, apropriação de matéria e subversão.
\end{abstract}

Palavras-chave: Marcial; Ovídio; poética clássica; emulação; intertextualidade.

Abstract: This article analyzes a set of Martial's passages in which this author emulates the poetry of Ovid, with the purpose of understanding the strategies in the appropriation of material from his works. Starting from the classification of Cenni (2009), which divides the passages of Martial's corpus into citations (citazioni) and echoes (riecchegiamenti), we can conclude that Martial's procedures are more complex than the dichotomy proposed by the Italian researcher, and we propose a typology that classifies the activity of emulation of Ovid by Martial in reminiscence, juxtaposition, appropriation of subject, and subversion.

Keywords: Martial; Ovid; classical poetics; emulation; intertextuality.

$\mathrm{O}$ artigo que se segue pretende participar da comemoração do bimilenário ovidiano, homenageando um poeta tão importante na formação das letras tanto clássicas quanto vernáculas, cuja morte se deu em algum ponto do biênio 17-18 d.C. 
A emulação, da forma como é conhecida e discutida no contexto das letras gregas e romanas, pressupõe um esforço ativo e consciente uma atitude -, por parte do poeta que se propõe a compor, de reconhecer que há algo no repertório anterior que deve ser tido como modelar e levado em consideração na formação do novo texto. Como bem aponta Hinds (1998, p. xi) "the words which we use have always been used before; we never have a monopoly on their contexts and connotations", de modo que qualquer texto lido é suscetível de comparecer, mesmo que de forma impensada, em um texto posterior. Além disso, contudo, a emulação é programática para os autores da Antiguidade clássica. Essa afirmação é particularmente verdadeira no caso dos dois poetas que este artigo discute, Ovídio e Marcial.

Ovídio, cuja obra expande todos os limites do gênero elegíaco, e além disso excele em perfeição épica nas Metamorfoses, é leitor ávido de poesia e se apropria de material de muitos autores, tanto os mais afastados, como Hesíodo, quanto aqueles cronologicamente muito próximos dele, tais como Catulo, chegando até aos seus contemporâneos, a cuja performance provavelmente teve acesso, como Propércio e Virgílio. Não bastasse essa abundância, que o leitor apto de seu período estava em condições de perceber, o poeta não se exime de discutir poesia: o Livro II das Tristes, por exemplo, comenta a matéria erótica de muitos autores gregos e latinos, e não teme coroar sua lista com a frase: "a estes eu segui" (Tr., II, 467: his ego successi), que pode se referir aos dois autores comentados mais imediatamente (Propércio e Tibulo), ou à lista mais extensa que vinha compondo.

Marcial, da mesma forma, incorpora uma ampla variedade de repertório dos seus antecedentes, entre os quais Ovídio é um dos mais destacados, e, tanto quanto ele, destaca-se por produzir reflexão crítica sobre poesia com alguma frequência. Nos epigramas metalinguísticos de Marcial, Ovídio é apontado algumas vezes como modelo, principalmente (mas não exclusivamente) de matéria erótica.

\footnotetext{
1 "As palavras que usamos sempre passaram por uso anterior; nunca temos monopólio sobre seus contextos e conotações”. Tradução minha.
} 
A discussão teórica sobre a forma como Marcial lê e se apropria da obra de Ovídio não é nova: já em 1877, Zingerle publica um estudo exaustivo intitulado Martial's Ovid-Studien, que cataloga 160 passagens do bilbilitano que se relacionam à obra do peligno. Desde então, diversos pesquisadores têm acrescentado novos trechos à lista (um recenseamento mais detalhado pode ser encontrado em Cenni, 2009). São dignos de menção, pela relevância da observação crítica e pelo aporte metodológico, o comentário de Mario Citroni (1975) ao Livro I de Marcial, em que essa observação está relacionada a uma observação integral do primeiro Epigrammaton Liber, o livro de Fitzgerald (2007), Martial and the World of Epigram, que dedica um capitulo inteiro à relação de Marcial com Catulo e Ovídio, e o artigo de Stephen Hinds (2007), "Martial's Ovid / Ovid's Martial", cuja interpretação por si só é inovadora e se enriquece quando confrontada com o livro do mesmo autor sobre alusão e intertexto (HINDS, 1998), o qual, vinte anos após a sua primeira publicação, segue contendo algumas das reflexões mais instigantes sobre o tema.

O objetivo deste artigo é observar, dentro do vasto repertório que, na obra de Marcial, foi relacionado ao influxo ovidiano, algumas passagens que ajudem a identificar os processos compositivos através dos quais o epigramatista incorpora o texto de Ovídio ao seu.

Duas preocupações centrais devem ser apontadas antes de chegarmos aos textos. Primeiramente, este artigo não tem pretensão nenhuma de se apresentar como catálogo nem de se filiar ao estudo das fontes com os quais se produziram muitos equívocos metodológicos no século XIX: ainda que se ignorasse a limitação teórica destes estudos, para essa recusa basta apontar que o catálogo de fontes, neste caso, já existe, conforme mencionamos acima, e é compulsável nas principais bibliotecas eletrônicas. Em seguida, e neste caso trata-se de um problema mais complexo, não se pretende fazer uma leitura das passagens como declaração de intenções. Pretende-se, com isso, não negar a existência do autor, mas sim fugir da pretensão biografista de que se conheça a finalidade do texto na concepção do autor, procurando antes o resultado de leitura na produção dos epigramas, isto é, como Marcial coloca Ovídio entre sua inuentio e si mesmo. 
Nossa interpretação das passagens parte das categorias propostas por Cenni (2009), que divide as passagens analisadas em citações (citazioni) e ecos (riecchegiamenti).

\section{Entre as palavras e a matéria}

No poema de abertura do primeiro livro de epigramas de Marcial, encontra-se uma das expressões mais famosas do poeta: toto notus in orbe. Vejamos o poema na íntegra:

Hic est quem legis ille, quem requiris,

Toto notus in orbe Martialis

Argutis epigrammaton libellis:

Cui, lector studiose, quod dedisti

Viventi decus atque sentienti,

Rari post cineres habent poetae.

Sou aquele que lês e que reclamas,

Marcial, conhecido em todo o mundo

por livrinhos argutos de epigramas,

a quem, leitor atento, concedeste

ainda com juízo e vivo a glória

que tem raro poeta após as cinzas. ${ }^{2}$

A hipérbole contida no segundo verso não escapa à atenção dos investigadores, os quais, em pelo menos duas circunstâncias, chegam ao ponto de elegê-la para nomear estudos sobre o autor, ${ }^{3}$ uma vez que caracteriza um discurso recorrente na poética de Marcial. O que, contudo, não parece ter sido abordado por outros pesquisadores é que este verso ecoa uma passagem das Metamorfoses de Ovídio (I, 6): unus erat toto naturae uultus in orbe ("a natureza tinha, em todo o orbe, um

\footnotetext{
${ }^{2}$ As traduções aqui apresentadas, salvo indicação expressa, são de minha autoria. As traduções dos epigramas de Marcial são aqui citadas a partir de Cairolli (2014).

${ }^{3}$ Referimo-nos aqui à publicação alemã vinda à luz em 1998, Toto notus in orbe: Perspektiven der Martial-Interpretation, organizada por Grewing, e a portuguesa de 2004 Toto notus in orbe Martialis: celebração de Marcial 1900 anos após a sua morte, organizada por Brandão, Pimentel e Leão.
} 
só rosto", na tradução de Raimundo Carvalho). Estamos aqui no início do épico ovidiano, no segundo verso da narrativa, após os quatro versos da proposição.

Nesta passagem, parece-nos que, muito mais do que a perspectiva de qualquer alteração de sentido no epigrama, o subtexto ovidiano deve ser entendido como um eco, uma reminiscência, algo que se recupera de forma vaga - diríamos até inconsciente, se não se tratasse de anacronismo - de um repertório bem frequentado: não é excessivo supor que o poeta, planejando o prefácio de seu livro, lesse o que seus principais modelos haviam feito.

A afirmação acima deve ser sustentada por uma investigação cautelosa. Por um lado, nossa primeira impressão é de que estamos diante de problemas de interpretabilidade como os apontados por Hinds (1998, p. 17), a saber, que estamos diante de certas confluências linguísticas que são parte do modo de falar de uma sociedade e, como tais, não são reportáveis a tal ou qual autor. Toto in orbe, que em português corrente se traduz por "no mundo inteiro", parece ser uma destas expressões.

No entanto, uma observação um pouco mais detalhada pode ajudar a sustentar nossa afirmação. A observação de outros poetas mostra que, mesmo se tratando de uma expressão relativamente comum, não é utilizada de forma homogênea por eles. A título de exemplo, o sintagma totus orbis ("mundo inteiro"), em qualquer uma de suas flexões, separado ou não por outras palavras, é utilizado apenas quatro vezes na Eneida (I, 457; IV, 231; VII, 258 e X, 546), todas as vezes no acusativo singular; em Lucrécio, cinco vezes (II, 543; III, 410; V, 691; V, 1166; VI, 629); Propércio recorre a ela apenas uma vez (III, 11, 57); Estácio, nas Silvas, também a usa somente uma vez (III, 4, 39).

A frequência do sintagma é relativamente baixa em comparação a Marcial e Ovídio. O epigramatista recorre a ele onze vezes (I, 1; II, 66; V, 13; V, 74; VI, 61; VI, 64; VII, 17; VII, 29; VIII, 36; VIII, 61 e IX, 31), sete das quais em contexto metalinguístico - em passagens que, além disso, emulam a poesia metalinguística do sulmonense. Ovídio, só nas Metamorfoses, recorre a ele nada menos que dezoito vezes (I, 6; I, 187; I, 203; I, 726; II, 335; II, 642; IV, 624; V, 489; V, 556; VI, 699; VII, 59; IX, 741; XII, 63; XII, 617; XIII, 588; XII, 622; XIV, 680; XV, 177). 
Como se pode notar, não há qualquer relação genérica ou cronológica que pudesse suportar esse maior ou menor uso da expressão: o epos de Ovídio recorre à expressão muito mais do que Virgílio ou Lucrécio; Marcial e Estácio, no mesmo período, não partilham do mesmo vocabulário; mas Marcial e Ovídio, em épocas diferentes e gêneros afastados, sim.

A prova decisiva surge quando a passagem volta a comparecer em Marcial, no epigrama II, 66. Aqui, o epigrama trata do penteado de uma certa Lálage. Veja-se o primeiro dístico deste poema:

Vnus de toto peccauerat orbe comarum anulus, incerta non bene fixus acu:

Desarranjara-se um só cacho em todo o mundo de cabelos, mal-fixa a agulha incerta.

Confrontado com o início do poema de Ovídio, veja-se como os sentidos se amplificam:

Ante mare et terras et quod tegit omnia caelum unus erat toto naturae uultus in orbe, quem dixere chaos: rudis indigestaque moles nec quicquam nisi pondus iners congestaque eodem non bene iunctarum discordia semina rerum.

(Ov., Met., I, 5-9).

Antes do mar, da terra e céu que tudo cobre, a natureza tinha, em todo o orbe, um só rosto a que chamaram Caos, massa rude e indigesta; nada havia, a não ser o peso inerte e díspares sementes mal dispostas de coisas sem nexo. ${ }^{4}$

Ovídio começa seu poema descrevendo o início dos tempos, quando nada existia e todas as coisas estavam potencialmente prontas para surgir de uma massa disforme primordial que recebe o nome de Caos. O leitor familiar com as Metamorfoses de Ovídio, ao ser estimulado pela sonoridade dos versos de Marcial, muito provavelmente reconheceria a

\footnotetext{
${ }^{4}$ Tradução de Raimundo Carvalho.
} 
passagem, estando apto a relacionar o complicado penteado de Lálage com a massa rude e indigesta que antecede a ordem do mundo. ${ }^{5}$

Aqui, o verso 6 de Ovídio é imitado no verso 1 de Marcial ("unus erat toto naturae uultus in orbe"; "unus de toto peccauerat orbe comarum") e o verso 9 é seguido de perto pelo verso 2 ("non bene iunctarum discordia semina rerum"; "anulus, incerta non bene fixus acu").

A passagem de Ovídio devia ser bem frequentada por Marcial. O uso dela em II, 66 testemunha em favor de que ela seja o modelo de I, 1, mas, além disso, nos aponta para o problema da impossibilidade de dissociar, em um poeta, o autor do leitor. Desta forma, partindo de uma passagem em que a percepção de uma reminiscência verbal é um fato de proporções poéticas reduzidas, chegamos a uma passagem em que ocorre reminiscência verbal com justaposição de sentido. Em outras palavras, a produção de sentido poético depende (ou ao menos se beneficia) do reflexo do texto imitado sobre o imitador.

Diversos exemplos, apenas nos poemas iniciais do Livro I de Marcial, dão a dimensão da frequente leitura de Marcial a Ovídio. Em I, 2, por exemplo, Marcial faz uma engenhosa propaganda do livreiro que vende seus livros, da qual destacamos os versos 5-6:

Ne tamen ignores ubi sum uenales et erres

urbe uagus tota, me duce certus eris. ${ }^{6}$

Mas pra que saibas quem me vende sem errar a Urbe inteira, te guio ao lugar certo.

Como se pode notar, o poeta retoma o mesmo sintagma toto in orbe que usara poucos versos antes, com a diferença de que em lugar de orbe, trata-se da urbe. A passagem que deve ser lida em conjunto com este dístico é novamente das Metamorfoses de Ovídio. Não se trata, contudo, do início do epos, mas de uma narrativa contida no Livro XIV, o mito de

\footnotetext{
${ }^{5}$ Vale a pena recordar que Marcial produziu a maior parte de sua poesia sob a dinastia dos Flávios, época em que, nos bustos femininos, abundam as representações de densos arranjos de cabelos por cima da cabeça, penteados rebuscados que suscitariam a analogia.

${ }^{6}$ Grifos meus.
} 
Pomona e Vertumno. No relato ovidiano, Vertumno se transforma em uma velha para conseguir falar com Pomona, convencendo-a a não rejeitar as investidas de um amante. No centro do discurso da falsa idosa está a recomendação de um excelente partido, justamente, Vertumno. Estes são os termos (vv. 678-680):

Vertumnumque tori socium tibi selige! pro quo me quoque pignus habes (neque enim sibi notior ille est, quam mihi); nec passim toto uagus errat in orbe [...].

e elege ao matrimônio Vertumno, por quem tens também meu penhor, que ele não se conhece melhor que eu, nem por todo o mundo vaga, errante.

A semelhança das passagens é notável, e por si só apontaria para uma relação entre os textos. Contudo, o que se destaca é que Marcial, para fazer a própria propaganda, recorra à leitura de outra narrativa em que um personagem alardeia seus próprios méritos, ou seja, a retomada lexical do texto de Ovídio serve para incorporar a audácia e a argúcia de Vertumno à da persona epigramática.

Se a correlação dos textos permite um confronto mais próximo, na continuação da fábula de Ovídio o discurso do deus não convence a ninfa: ele acaba por retornar à sua antiga forma e se prepara para violar Pomona, mas a simples contemplação da beleza de Vertumno faz que ela se enamore dele (OV., Met., XIV, 765-771). Se os epigramas tiverem os divinos atributos de Vertumno, o leitor pode relevar o dolo de sua argúcia e se apaixonar por eles mesmo assim. Temos, portanto, nesta passagem, mais um exemplo do procedimento que chamamos acima de justaposição de sentidos.

Acrescentamos à lista outro epigrama de caráter prefacial, o segundo poema do Livro dos espetáculos, uma peça de valor retórico indiscutível na qual Marcial demonstra como o espaço subtraído aos romanos por Nero para a construção da Domus aurea é devolvido ao povo na forma de prazeres como Anfiteatro Flávio (o Coliseu) e sua adjacente estátua, além de um pórtico e termas. Onde hoje se situa o símbolo máximo de Roma: 
inuidiosa feri radiabant atria regis

unaque iam tota stabat in urbe domus.

(MARCIAL, Espetáculos, 2, v. 3-4)

brilhava o átrio odioso do bruto tirano, a única casa da cidade inteira.

Aqui, novamente, o oxímoro ovidiano é utilizado para enfatizar o contraste entre antes e depois: assim como antes tinha um único aspecto o que depois se tornou a infinita pluralidade do universo, o Coliseu, casa de todos os romanos, substitui o que antes era a casa de uma única - e, diríamos, caótica - pessoa.

É difícil (se é que se pode considerar desejável) dissociar o eco, a reminiscência, de um procedimento de justaposição e incorporação de sentidos poéticos. A pretensão de um estudioso de reconhecer os níveis de leitura de um autor sobre outro só pode ser justificada por aquilo que Hinds (1998, p. 18) chama de "old philological instinct to police and protect that idea of allusive control". ${ }^{7}$ Supor que o autor controla todos os níveis da produção do poema é desprezar a dinâmica da linguagem e pode causar embaraços: já desde o compêndio de Zingerle apontamse como relacionados os versos Mart. Epig. I, 3, 5 e Ov., Met., VIII, 526, do qual Marcial imita a expressão iuuenesque senesque, "tanto os jovens quanto os velhos", (a qual, não custa dizer, também comparece em Pérsio, Sat., V, 64: puerique senesque, "tanto os meninos quanto os velhos"). A passagem de Ovídio integra a narrativa do mito de Meleagro, particularmente a parte em que se descreve a comoção geral do povo calidônio pela morte de seu herói. Esses versos também são notáveis por imprimirem ritmo narrativo através da repetição da conjunção aditiva enclítica -que (nos versos 520-527 ela é repetida catorze vezes). O mito de Meleagro é familiar a Marcial, que se refere a ele diversas vezes em sua obra, como, por exemplo, no Livro dos espetáculos, poemas 15 e 27, cronologicamente anteriores ao Livro I. Confronte-se os versos 526-527 de Ovídio:

7 “Um velho instinto filológico de policiar e proteger aquela ideia de controle da alusão”. Tradução minha. 
Alta iacet Calydon: lugent iuuenesque senesque, uulgusque proceresque gemunt [...].

A alta Cálidon jaz: choram jovens e velhos, gemem o povo e os nobres [...].

com I, 3, 5-6 de Marcial:

Maiores nusquam rhonchi: iuuenesque senesque et pueri nasum rhinocerotis habent.

Lugar algum faz mais barulho: jovens, velhos, guris têm nariz de rinoceronte.

Aquele poema fala sobre o luto de um povo, este sobre a arrogância de outro: decida quem puder como estes textos se entretecem.

Outro grupo de passagens em que Marcial lê Ovídio difere dos exemplos que apresentamos acima por priorizar a imitação da matéria, em vez de se centrar nas palavras (ainda que a apropriação lexical possa fazer parte deste procedimento). A apropriação dos conceitos, dos lugares ovidianos é recurso recorrente em Marcial.

Uma das passagens favoritas do epigramatista é um dístico da elegia III, 15 dos Amores de Ovídio. Este é o poema em que o poeta elegíaco declara o encerramento de sua produção erótica, reclamando para si uma matéria mais grave. Para efetuar tal transição, a persona se despoja do seruitium à mulher amada da elegia erótica e rememora a condição de cidadão: sua gens é antiga e seus méritos pessoais não são só os militares, e tanto o poeta quanto a família pertencem a uma nação tradicionalmente fiel aos romanos. A relação que o poeta estabelece com sua terra é de mão dupla: sua terra o engrandece e ele engrandece sua terra. Assim, nos versos 7-8, declara:

Mantua Vergilio, gaudet Verona Catullo;

Paelignae dicar gloria gentis ego.

Virgílio alegra Mântua; Catulo, Verona;

dirão que sou a glória dos pelignos.

A imagem do poeta que agrada a sua cidade e a aproximação entre o poeta e seus modelos são dois lugares que Marcial imita com 
muita frequência. Há usos em que o eco prevalece, como em XIV, 195, dístico que acompanha - ou substitui - um livro de Catulo feito presente durante as Saturnais:

\section{Tantum magna suo debet Verona Catullo, quantum parua suo Mantua Vergilio. \\ Verona, a grande, deve tanto ao seu Catulo quanto a pequena Mântua ao seu Virgílio.}

que, por sua vez, é recuperado no epigrama I, 7, vv. 4-5:

Tanto Stella meus tuo Catullo quanto passere maior est columba.

Meu Estela é maior que o teu Catulo tal qual maior do que o pardal é a pomba.

ambas testemunhando não apenas a leitura de Ovídio que é objeto deste estudo, mas também que a leitura de Catulo, para Marcial, além de direta, recebe interferência da forma como o sulmonense lê aquele poeta.

Além destes casos, é muito digno de nota o caso do poema I, 61, que, além de composto em um dístico de escazonte seguido por dímetro jâmbico (algo que ecoaria os experimentos rítmicos dos Epodos de Horácio e retomaria o epigrama I, 49 pelo eco do dístico epódico), toma por ponto de partida a passagem ovidiana:

Verona docti syllabas amat uatis,

Marone felix Mantua est, censetur Aponi Liuio suo tellus

Stellaque nec Flacco minus, Apollodoro plaudit imbrifer Nilus,

Nasone Paeligni sonant, duosque Senecas unicumque Lucanum

facunda loquitur Corduba, gaudent iocosae Canio suo Gades,

Emerita Deciano meo:

te, Liciniane, gloriabitur mostra

nec me tacebit Bilbilis. 
Verona ama em seu douto vate os metros,

Mântua é feliz com Marão,

por Lívio a terra de Ápono se estima,

não menos por Flaco e Estela,

chuvoso, o Nilo aplaude Apolodoro,

cantam Nasão os Pelignos,

de dois Sênecas, do único Lucano

fala Córdoba fecunda,

Cádiz jocosa ao Cânio seu encanta

e Emérita, o meu Deciano:

por ti se jactará, Liciniano,

e não me calará Bílbilis.

Os dois favoritos de Ovídio são aqueles com que Marcial inicia seu poema, contudo, ao contrário do que se viu em XIV, 195, o poema não se restringe a eles. O poeta identifica o lugar comum do escritor amado por sua cidade de origem, desenvolvido por Ovídio, e o amplifica, construindo um pinax, isto é, um poema do tipo catálogo. Este é possivelmente o mais curioso de quantos podemos encontrar nos Epigramas, pois o atributo que agrega os autores à coleção não é poético, juntando-se no poema o épico de Virgílio ou Lucano, o epigramático de Catulo, o historiográfico de Lívio, o filosófico de Sêneca filho ou o retórico de Sêneca pai, mas o fato de serem notáveis provinciais que desfrutaram de fama em Roma. Há uma ponte significativa entre os autores cisalpinos (Catulo, Virgílio, Lívio, Flaco e Estela) e os autores hispânicos, representada pelos não cisalpinos Apolodoro, autor egípcio de difícil identificação, e o próprio Ovídio. Ao fim, toda a longa lista é uma preparação para que Marcial eleve o seu interlocutor, e, finalmente, a si mesmo, ao mesmo patamar de alvos do amor de sua cidade, Bílbilis.

Aqui, Marcial identifica e amplifica o tópos de Ovídio: o lugar que um poeta quer ocupar diante da sua audiência se define em grande medida pelo lugar que os seus modelos ocupam diante dela, ou melhor, pela forma como se descreve e declara esses modelos. Assim, não bastará a Marcial, provincial orgulhoso, dizer que espera muito amor de seus concidadãos, mas sim que ele espera o mesmo amor que os veronenses devotam a Catulo. Estamos diante, portanto, de um exemplo de apropriação de 
matéria, na mesma medida em que o também famoso epigrama $X, 103$, no qual, uma década depois, o poeta indaga se efetivamente alcançou a estima dos seus municipes:

Municipes Augusta mihi quos Bilbilis acri monte creat, rapidis quem Salo cingit aquis, ecquid laeta iunat uestri uos gloria uatis? Nam decus et nomen famaque uestra sumus, nec sua plus debet tenui Verona Catullo meque uelit dici non minus illa suum. Quattuor accessit tricesima messibus aestas, ut sine me Cereri rustica liba datis, moenia dum colimus dominae pulcherrima Romae: mutauere meas Itala regna comas. Excipitis placida reducem si mente, uenimus; aspera si geritis corda, redire licet.

Concidadãos que a Augusta Bílbilis criou no alto monte, cingidos por Salão veloz, a glória deste vate lhes agrada? Hoje sou sua glória, nome e fama: pois nem Verona deve mais ao seu Catulo nem quer menos ouvir que sou seu filho. Trinta e quatro verões transcorreram, sem mim rústico voto a Ceres ofertaram e eu vivi nos belíssimos muros de Roma: na Itália, branquearam meus cabelos. Se me esperam com ânimo plácido, eu vou; se nutrem corações duros, eu volto.

Preparando-se para voltar à sua terra natal, o poeta indaga se os seus concidadãos estimam toda a fama que ele alcançou. Nos versos 3-6, além da analogia ovidiana ao exemplar amor municipal de Verona a Catulo, Marcial propõe uma inovação do tópos: a própria Verona, que tanto se ufana de seu Catulo, também se ufanaria de considerar Marcial um dos seus. Em outras palavras, a própria terra de Catulo seria a primeira dizer que Marcial superou aquele poeta. 
É importante notar, como estes dois exemplos deixam claro, que apropriação da matéria é o lugar por excelência da emulação, uma vez que se mostra não só a apreciação do que se reconhece como o melhor na obra de um autor modelar, mas também a disposição de se fazer algo a mais com o material colhido.

Uma especialização desse procedimento, que leva a apropriação de matéria aos últimos limites, é o que pode ser verificado no epigrama II, 41. Este é um poema de extensão incomum na obra de Marcial (23 versos) que não passou desapercebido pelos pesquisadores, entre outros fatores por conter uma das poucas referências nominais a Ovídio. Embora longo, é um poema que merece a leitura integral:

'Ride si sapis, o puella, ride'

Paelignus, puto, dixerat poeta:

sed non dixerat omnibus puellis.

Verum ut dixerit omnibus puellis, non dixit tibi: tu puella non es, et tres sunt tibi, Maximina, dentes, sed plane piceique buxeique.

Quare si speculo mihique credis, debes non aliter timere risum, quam uentum Spanius manumque Priscus, quam cretata timet Fabulla nimbum, cerussata timet Sabella solem. Voltus indue tu magis seueros, quam coniunx Priami nurusque maior;

mimos ridiculi Philistionis et conuiuia nequiora uita et quidquid lepida procacitate laxat perspicuo labella risu. Te maestae decet adsidere matri lugentique uirum piumue fratrem, et tantum tragicis uacare Musis. At tu iudicium secuta nostrum plora, si sapis, o puella, plora. 
'Ri se souberes, ó menina, ri'

o poeta peligno, creio, o disse.

Mas não o disse a todas as meninas.

$\mathrm{Na}$ verdade, dizendo a todas elas, não o disse a ti: tu não és menina, e o que tens, Maximina, são três dentes, mas totalmente escuros e amarelos. Portanto, se no espelho crês e em mim, deves temer, não de outra forma, o riso como a mão teme Prisco, Espânio, o vento, branca em greda, Fabula teme a nuvem e, alvaiadada, teme o sol Sabela.

Da expressão mais severa te reveste, mais que a esposa de Príamo e mais que a nora.

Os mimos do risível Filistião evita, e os mais devassos convidados e tudo que, com lépida insolência, deixa evidente o riso nos teus lábios. Convém a ti que assistas à mãe triste aos pios irmãos, aos homens que lastimam e só das musas trágicas te ocupes.

Mas tu, porque seguiu meu julgamento, chora, menina, se souberes, chora.

A passagem a que este epigrama mais diretamente se refere está no terceiro livro da Ars Amatoria de Ovídio (vv. 279-282), na qual se aproximam dentes, riso e choro:

si niger aut ingens aut non erit ordine natus dens tibi, ridendo maxima damna feres.

quis credat? discunt etiam ridere puellae, quaeritur atque illis hac quoque parte decor.

Se nasceram enormes, negros ou disformes teus dentes, grandes danos causa o riso.

Quem diria? a mulher também aprende a rir, mesmo nisso um decoro é procurado. 
Os preceitos ovidianos sobre o riso, como vemos aqui, alternam recomendações sobre o desejável e descrições do indesejável, tais como o riso que deforma as feições do rosto, (287) ou aquele do som rouco (289), e é seguido pela discussão sobre como chorar (v. 291: Quo non ars penetrat? discunt lacrimare decenter, "onde a arte não penetra? elas aprendem a chorar adequadamente"), habilidade que, assim como o riso, pode mover seu amator na direção que a elas seja mais conveniente.

O que é mais notável, a nosso ver, no procedimento de Marcial é que aqui ele parodia a erotodidaxis de Ovídio para produzir um efeito absolutamente epigramático: a hipérbole - figura epigramática por excelência - começa no próprio nome da personagem invectivada, Maximina, a qual, como bem aponta Hinds (2007, p. 117) tem seu nome tirado da expressão maxima damna do dístico ovidiano, e na descrição do supremo horror de seus dentes: são apenas três (v. 6) e são totalmente (v. 7: plane) escurecidos e amarelados. É um caso concreto (e não uma observação geral, como em Ovídio) que faz Marcial assumir a função de magister e ensinar o quanto Maximina deve temer o riso, a expressão que deve assumir e os lugares e pessoas que deve frequentar para que sua deformidade não cause o seu mal. A conclusão do aprendizado é que Maximina deve chorar.

Enquanto em Ovídio o que se observa é o arrolamento de temas que devem ocupar as suas discípulas e, portanto, riso e choro se apresentem como atividades contíguas, em Marcial o choro é a consequência de toda a preceptiva que ele demoradamente desenvolve: Maximina não chora ou ri para lograr seduzir seu amante, como faz uma discípula de Ovídio, mas sim chora por chegar a saber que não pode rir. O lumen, efeito brilhante do fechamento epigramático, baseia-se na inversão da estrutura circular: o poeta mantém a estrutura do primeiro verso no último, trocando apenas o verbo ride por plora. O efeito do verso é realçado pelo duplo sentido do verbo sapis, que, na abertura, significa "ter sabor", isto é, entendimento do jogo da sedução, ao passo que no fechamento significa "ter prudência".

Aqui, a presença de Ovídio no poema chama ostensivamente a atenção do leitor para um lugar e um modo de falar da aparência feminina, com o que fica realçado o caminho do epigrama em outra direção, amplificando o sentido do texto com isso. O que se observa aqui é um 
exemplo notável de subversão da matéria, um tipo de apropriação em que todos os limites do que se espera que determinados lugares possam ocupar devido à sua especificidade (como nesse caso a discussão erotodidática da aparência de uma mulher) são ultrapassados em sua nova enunciação.

\section{Discussão}

Tentamos descrever, através do conjunto de exemplos apresentados, como o texto de Ovídio comparece em Marcial de formas diferentes, tomando-se como elemento central desta aproximação a seleção lexical ou a incorporação de matéria.

O primeiro procedimento que descrevemos é o de reminiscência verbal, isto é, quando se verifica o uso de palavras, ou conjuntos de palavras, identificáveis como parte de um texto anterior. Esse tipo de uso, que por vezes pode ser até inconsciente, pode estar relacionado ao manuseio frequente do texto-fonte, a uma investigação por parte do poeta de material linguístico que atenda às necessidades compositivas do momento ou mesmo ao propósito de reconhecer uma construção apreciável do autor modelo por meio da repetição. O próprio Ovídio, se se tomar como fatual a anedota de Sêneca, o Retor (Suas., 3, 7), declarava apreciar de tal forma uma expressão de Virgílio que a usou em sua tragédia (a hoje perdida Medeia), non subripiendi causa, sed palam mutuandi, hoc animo ut uellet agnosci ("não para roubá-la, mas tomá-la emprestada abertamente, com o propósito de que fosse reconhecida").

Casos em que a circulação de material é tão abundante, como se verifica de Ovídio para Marcial, levam à discussão do nível em que a observação destes fenômenos deve ser entendida como algo que produz sentido. Quando considerado um percurso interpretativo possível, surge ainda a hipótese de que o sentido esteja relacionado à intenção ou às finalidades (isso quando a crítica postular sua capacidade de discuti-las) mais do que à história da recepção, que o reconhecimento de tais ou quais proximidades lexicais entre dois autores seja algo esperado do público ou a demonstração de refinamento e erudição da recepção posterior. Em outras palavras, se esta possibilidade integra aquilo que Horácio define como aptum ou se a investigação científica está forçando o objeto. 
Um grupo privilegiado de textos em que há proximidade lexical é aquele que descrevemos como justaposição de sentidos. O conceito é digno de nota tanto na antiguidade quanto na atualidade. Para os antigos, o uso mais simbólico da justaposição é aquele que se observa na numismática. As moedas romanas não possuem valor facial como o dinheiro contemporâneo, uma vez que seu valor é dado pela relação dos metais que compõem as peças em circulação. Disso resulta que uma moeda tem duas faces em que imagens podem figurar. Normalmente, no período imperial, um lado é reservado à representação do imperador ou de membros de sua família, cabendo na outra face a representação de deuses, edificações, eventos, que estabelecem troca de sentido com a efígie que os acompanha.

A poesia latina recorre à justaposição com frequência, como, por exemplo, os poemas em que Catulo invectiva Mamurra, general romano, mas nunca deixa de mencionar ao lado dele seu comandante, Júlio César. Marcial maneja o recurso com extrema perícia, por exemplo, em poemas do Livro I (14 e 22) em que narra um espetáculo muito apreciado no período: um leão permite a uma lebre que entre e saia na sua boca sem mordê-la. Tal milagre é possível porque o imperador era proprietário do felino.

Modernamente, para restringirmos exemplos a apenas um, Barthes descreve a formação do mito por um procedimento semelhante a este:

No mito, pode encontrar-se o mesmo esquema tridimensional de que acabei de falar: o significante, o significado e o signo. Mas o mito é um sistema particular, visto que ele se constrói a partir de uma cadeia semiológica que já existe antes dele: é um sistema semiológico segundo. O que é signo (isto é, a totalidade associativa de um conceito e de uma imagem) no primeiro sistema, transforma-se em simples significante no segundo. (BARTHES, 2001, p. 136). 
Ao nomear o procedimento como justaposição de sentidos, privilegiamos, na relação entre os textos, a ideia de que as informações circulam entre eles com mais liberdade do que se se pensasse em outros termos que descrevem procedimentos análogos, como símiles e metáforas, ou forma e conceito, como no exemplo de Barthes. Os dois textos são plenamente funcionais sozinhos, mas são colocados juntos sem nenhum termo de coordenação ou subordinação - o elemento coesivo aqui é a proximidade lexical, que pode muito bem não ser reconhecida por um leitor pouco familiarizado com algum dos textos, ou ser reconhecida de formas diferentes, no caso de o leitor não acessar os textos na mesma ordem cronológica de sua circulação. No esquema barthesiano, há uma linearidade interpretativa em que se parte do sistema semiológico primário para o secundário. Ao pensar dois textos em termos de justaposição, por sua vez, o fluxo de atributos circula em ambas as direções: no exemplo que mostramos, o leitor do epigrama II, 66 é convidado a observar o penteado de uma mulher como se fosse o caos primordial de Ovídio, mas ao mesmo tempo o epigrama passa a permitir que o leitor de Ovídio pense o caos primordial como um penteado feminino do período flaviano.

Ao lado das aproximações entre textos em que o elemento predominante é a seleção lexical, vimos exemplos em que a aproximação de matéria, mais do que sua consequente aproximação lexical, era o aspecto mais relevante. A imitação da matéria é um tema discutido desde a própria Antiguidade, ocupando espaço significativo não só na Poética (Aristóteles e Horácio, com efeito, dedicam espaço a estas questões), como na Retórica, que dedica sua primeira parte à Invenção, isto é, ao achamento da matéria que integrará o discurso. $\mathrm{O}$ caso que elegemos para exemplo (Ov., Am., III, 15) é um dos mais produtivos em Marcial, dado que, em sua contínua reutilização nota-se, primeiro, o reconhecimento de uma passagem de Ovídio como um lugar específico, e, em seguida, em sua apropriação por Marcial, procedimentos como repetição (XIV, 195), amplificação (I, 61) e transformação do tópos (X, 103).

Deste último procedimento, apartamos uma última categoria, na qual a transformação extrapola os limites de gênero e até do próprio 
sentido do tópos em seu texto de partida, ao qual chamamos de subversão da matéria. Aqui, o material de um determinado autor é incorporado ao poema de modo a forçar contraste entre o primeiro texto e o segundo. No epigrama II, 41, exemplo por excelência desta operação, Marcial realça o sentido da sua invectiva ao induzir o leitor a observar junto a didática erótica de Ovídio, que segue um caminho diferente. Não é excessivo lembrar que a poesia epigramática não dependeria da licença de um poeta didático para se colocar na posição de magister: a persona epigramática descreve seu procedimento como docência em diversas ocasiões (docebo, "ensinarei", por exemplo, ocorre em IV, 56; XI, 99; XIV, 2; censeo, "julgo", em II, 13; V, 49; XI, 99 e XII, 61).

O exemplo de II, 41 é o mais extremo, já que este é o poema mais longo do Livro II, e essa posição pressupõe um tratamento diferenciado, não só do gênero epigramático, mas também dos autores modelares: em trabalho anterior, postulamos sobre a relação de diversos desses poemas mais longos com a sátira horaciana (CAIROLLI, 2015, p. 34), de forma similar à que este poema ocupa no Livro II. Outro exemplo, mais breve, pode ser aduzido do segundo livro das Tristes. Em 395-396, Ovídio, demonstrando como a matéria erótica está presente mesmo em gêneros tão avessos ao amor, como a Tragédia, declara:

Qui legis Electran et egentem mentis Oresten, Aegisthi crimen Tyndaridosque legis.

Tu que lês Electra e Orestes que perde a mente lês o crime de Egisto e da tindárida.

Calcado nele, Marcial inicia um epigrama programático (X, 4):

Qui legis Oedipoden caligantemque Thyesten, Colchidas et Scyllas, quid nisi monstra legis?

Tu, que lês o sombrio Tiestes, Cila, a Cólquide, e Édipo, por que lês somente monstros?

Em Ovídio, quem lê a narrativa dos irmãos Electra e Orestes, lê por extensão sobre os amores fraudulentos de sua mãe; em Marcial, quem lê uma narrativa sobre deuses e heróis, lê algo monstruoso. O contraste 
que as duas passagens juntas promovem servirá a Marcial para arrolar uma série de mitos que julga absurdos ou inúteis e que, além disso, são o contraponto da poesia epigramática, cujo tema não é o monstro do gênero trágico ou épico, mas o homem.

A categorização que propomos aqui não tem por objetivo montar um esquema fechado, algo que não caberia numa exposição dessa natureza. Pelo contrário, os procedimentos descritos são apresentados como hipóteses com as quais temos que descrever as estratégias de Marcial no manuseio dos textos de seus modelos. Sua validação depende, por um lado, de uma observação aprofundada da relação do poeta com outros autores; por outro, de que se verifiquem procedimentos análogos em outros poetas latinos ou no discurso teórico do período - tarefas que apenas parcialmente foram desenvolvidas pelos pesquisadores das Letras Clássicas.

\section{Referências}

BARTHES, R. Mitologias. 11. ed. Rio de Janeiro: Bertrand Brasil, 2001. CAIROLLI, F. Marcial e as Sátiras de Horácio. Hélade, Niterói, v. 1, n. 2, p. 30-38, 2015.

CAIROLLI, F. Marcial brasileiro. 2014. 498f. Tese (Doutorado em Letras) - Faculdade de Filosofia, Letras e Ciências Humanas, Universidade de São Paulo, São Paulo, 2014.

CARVALHO, R. N. B. Metamorfoses em tradução. 2010. 158f. Relatório (Pós-doutorado em Letras Clássicas) - Faculdade de Filosofia, Letras e Ciências Humanas, Universidade de São Paulo, São Paulo, 2010.

CENNI, C. Ovidio e Marziale tra poesia e retorica. 2009. 361f. Tese (Doutorado em Filologia Grega e Latina) - Universidade de Bolonha, Bolonha, 2009.

FITZGERALD, W. Martial, the World of the Epigram. Chicago: University of Chicago Press, 2007.

HINDS, S. Allusion and Intertext. Cambridge: Cambridge University Press, 1998. 
HINDS, S. Martial's Ovid / Ovid's Martial. Journal of Roman Studies, London, v. 97, p. 113-154, 2007.

MARTIAL. Marcus Valerius Martialis Epigrammata. Oxford: Clarendon Press, 1987.

MARTIALIS. Marcus Valerius Martialis Epigrammaton Liber I. Introduzione, testo, apparato critico e commento a cura di Mario Citroni. Florença: La Nuova Italia, 1975.

OVID. Tristia, Ex ponto. Translated by A. L. Wheeler. Cambridge: Harvard University Press, 1969.

OVID. Metamorphoses. Translated by F. J. Miller. Cambridge: Harvard University Press, 1999. 2 v.

OVID. The Art of Love and Other Poems. Translated by J. H. Mozley, rev. G. P. Goold. Cambridge: Harvard University Press, 1979.

VASCONCELLOS, P. S. Reflexões sobre a noção de "arte alusiva" e de intertextualidade no estudo da poesia latina. Clássica, v. 20, n. 2, p. 239-260, 2007.

ZINGERLE, A. Martials Ovidstudien. Innsbruck: Wagnersche Univ.Buchhandlung, 1877.

Recebido em: 19 de agosto de 2018. Aprovado em: 23 de novembro de 2018. 